\title{
BALANÇO ELETROLÍTICO PARA SUÍNOS MACHOS CASTRADOS EM CRESCIMENTO MANTIDOS EM AMBIENTE DE ALTA TEMPERATURA
}

\author{
Electrolyte balance of growing males castrated swines in a high temperature environment
}

\author{
Anilce de Araujo Brêtas ${ }^{1}$, Rony Antonio Ferreira², Valene da Silva Amarante Júnior ${ }^{3}$,

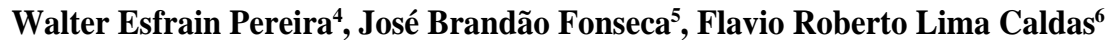

\begin{abstract}
RESUMO
Avaliou-se o efeito do balanço eletrolítico (BE) em rações com diferentes níveis de eletrólitos para suínos na fase de crescimento criados em alta temperatura. Foram utilizados 200 suínos machos castrados, com peso inicial de $25,3 \pm 1,3 \mathrm{~kg}$ e final de $68,8 \pm 3,4 \mathrm{~kg}$, distribuídos em delineamento experimental inteiramente casualizado com cinco tratamentos e quatro repetições com dez animais por unidade experimental, para a fase de crescimento T1(testemunha) ração sem suplementação de eletrólitos $191 \mathrm{mEq} / \mathrm{kg}$; T2 $\left(\mathrm{NaHCO}_{3}\right)$ ração suplementada bicarbonato de sódio $\left(\mathrm{NaHCO}_{3}\right) 250 \mathrm{mEq} / \mathrm{kg}$; T3 $\left(\mathrm{NaHCO}_{3}+\mathrm{KCl}\right)$ ração suplementada $\mathrm{NaHCO}_{3}$ e cloreto de potássio $(\mathrm{KCl}) 250 \mathrm{mEq} / \mathrm{kg}$; T4 $\left(\mathrm{NaHCO}_{3}\right)$ ração suplementada $\mathrm{NaHCO}_{3} 300 \mathrm{mEq} / \mathrm{kg}$; e T5 $\left(\mathrm{NaHCO}_{3}+\mathrm{KCl}\right) \mathrm{ração}$ suplementada com $\mathrm{NaHCO}_{3}$ e $\mathrm{KCl} 300 \mathrm{mEq} / \mathrm{kg}$. As variáveis avaliadas foram consumo de ração, ganho de peso, consumo de nitrogênio, consumo de lisina, eficiência de utilização de nitrogênio para ganho, eficiência de utilização de lisina para ganho, conversão alimentar e os parâmetros fisiológicos, frequência respiratória e temperatura retal. Foi coletado sangue para mensurar as concentrações sorológicas de $\mathrm{Na}, \mathrm{Cl}$ e K. A temperatura média foi $29,65 \pm 3,80^{\circ} \mathrm{C}$ com UR do ar $69,6 \pm 10,4 \%$, Temperatura do Globo Negro de $31,95 \pm 1,98^{\circ} \mathrm{C}$ e Índice de Temperatura do Globo Úmido em $80,51 \pm 2,44$. Os níveis de $\mathrm{BE}$ reduziram $(\mathrm{P}<0,05)$ consumo de ração e melhoram o consumo de nitrogênio. Os demais parâmetros de desempenho avaliados não foram afetados pelos diferentes balanços eletrolíticos $(\mathrm{P}>0,05)$. A correção do BE não influenciou o desempenho dos suínos.
\end{abstract}

Termos para indexação: Equilíbrio ácido base, estresse calórico, bicarbonato de sódio, cloreto de potássio.

\begin{abstract}
The effect of electrolyte balance (EB) in diets with different levels of electrolytes for growing swine under high environmental temperature was evaluated. Two hundred castrated pigs with initial weight of $25.3 \pm 1.3 \mathrm{~kg}$ and final weight of $68.8 \pm 3.4 \mathrm{~kg}$ were allotted in a completely randomized experimental design with five treatments and four replicates with 10 pigs per experimental unit, for the growing phase T1 (control) diet without electrolyte $191 \mathrm{mEq} / \mathrm{kg}$; $\mathrm{T} 2\left(\mathrm{NaHCO}_{3}\right)$ diet supplemented with sodium bicarbonate $\left(\mathrm{NaHCO}_{3}\right) 250 \mathrm{mEq} / \mathrm{kg} ; \mathrm{T} 3(\mathrm{NaHCO}+\mathrm{KCl})$ diet supplemented with $(\mathrm{NaHCO})$ and potassium chloride $(\mathrm{KCl}) 250 \mathrm{mEq} / \mathrm{kg}$; T4 $\left(\mathrm{NaHCO}_{3}\right)$ diet supplemented with $\left(\mathrm{NaHCO}_{3}\right) 300 \mathrm{mEq} / \mathrm{kg} ; \mathrm{T} 5\left(\mathrm{NaHCO}_{3}+\mathrm{KCl}\right)$ diet supplemented with $\mathrm{NaHCO}_{3}$ and $(\mathrm{KCl}) 300 \mathrm{mEq} / \mathrm{kg}$. The performance parameters evaluated were: feed intake, daily gain, nitrogen intake, lysine intake, efficiency of nitrogen use for weight gain, efficiency of lysine use for weight gain and the gainto-feed ratio and the physiological parameters, respiratory frequency and rectal temperature. Blood was colleted to measure serum concentration of $\mathrm{Na}, \mathrm{Cl}$ and $\mathrm{K}$. The average temperature was $29.65 \pm 3.80^{\circ} \mathrm{C}$ with relative humidity of $69.6 \pm 10.4 \%$, Black Globe Temperature of $31.95 \pm 1.98^{\circ} \mathrm{C}$ and temperature index calculated of $80.51 \pm 2.44$. The levels of EB decreased $(\mathrm{P}<0.05)$ the feed intake and improved nitrogen intake. The other performance parameters evaluated were not influenced by the treatment $(\mathrm{P}>0.05)$. The correction of EB did not influence the growth of the swine.
\end{abstract}

Index terms: Acid base equilibrium, heat stress, sodium bicarbonate, potassium chloride.

(Recebido em 16 de abril de 2009 e aprovado em 28 de julho de 2010)

\section{INTRODUÇÃO}

A região Nordeste do Brasil possui um rebanho suíno com alto potencial genético, porém com produtividade inferior em comparação às demais regiões do país, em virtude, principalmente, das características climáticas da região (Carvalho et al.,
2004). Nesse sentido, é importante considerar a temperatura ambiente como um dos principais elementos climáticos não só por causa do efeito direto sobre a intensidade das trocas térmicas corporais como indiretamente, pela influência que exerce sobre os demais componentes do bioclima.

\footnotetext{
'Universidade Estadual do Norte Fluminense/FAPERJ - Avenida Alberto Lamego - 2000 - Parque Califórnia - 28013-600 - Campos dos Goytacazes, RJ aabretas@yahoo.com.br

2Universidade Federal dos Vales do Jequitinhonha e Mucuri/UFVJM - Departamento de Zootecnia - Diamantina, MG

3Universidade Estadual do Maranhão/UEMA - Departamento de Zootecnia - São Luis, MA

${ }^{4}$ Universidade Federal da Paraíba/UFPB - Departamento de Ciências Fundamentais e Sociais - Areia, PB

${ }^{5}$ Universidade Estadual do Norte Fluminense Darcy Ribeiro/UENF - Laboratório de Zootecnia e de Nutrição Animal - Campos dos Goytacazes, RJ

${ }^{6}$ Universidade Estadual do Maranhão/UEMA - São Luis, MA
} 
O estresse por calor aumenta a exigência de energia para mantença, quando comparado à temperatura de conforto térmico, visto que maior quantidade desta é utilizada pelos suínos para dissipar calor, principalmente pelo aumento na frequência respiratória. Isso significa, que menos energia estará disponível para o crescimento dos animais.

A manutenção do equilíbrio ácido-básico tem grande importância fisiólogica e bioquímica, visto que as atividades das enzimas celulares, as trocas eletrolíticas e a manutenção do estado estrutural das proteínas são profundamente influenciadas por pequenas alterações na concentração hidrogeniônica $\mathrm{H}^{+}$do sangue (Macari et al., 1999). Dentre as alterações fisiológicas que podem influenciar sua produtividade, destaca-se o equilíbrio dos eletrólitos no fluido corporal. O balanço eletrolítico da ração pode exercer influência no equilíbrio ácido-básico e, consequentemente, afetar os processos metabólicos relacionados ao crescimento, à resistência a doenças, à sobrevivência ao estresse e ao desempenho do animal (Vieites et al., 2004). Segundo Mogin (1980), o sódio, potássio e cloreto são fundamentais na manutenção da pressão osmótica e equilíbrio ácido base dos líquidos corporais. Desta forma, para prevenção do desequilíbrio ácido básico, a suplementação de rações com eletrólitos como bicarbonato de sódio $\left(\mathrm{NaHCO}_{3}\right)$ e cloreto de potássio $(\mathrm{KCl})$ tem sido utilizada em regiões de clima quente.

Assim, objetivou-se avaliar o desempenho e parâmetros fisiológicos de suínos em crescimento mantidos em condições naturais de calor recebendo rações com diferentes balanços eletrolíticos.

\section{MATERIAL E MÉTODOS}

O experimento foi conduzido em uma suinocultura comercial localizada no município de São Luís - MA $\left(2^{\circ} 35^{\prime} \mathrm{S} ; 44^{\circ} 12^{\prime} \mathrm{W}\right)$ durante o período de calor (outubro a fevereiro) no ano de 2008 e 2009, época de maiores temperaturas na região.

Os animais foram alojados em galpão de alvenaria, coberto com telha de fibrocimento em duas águas, sem forro, com piso de cimento parcialmente ripado, dividido em baias iguais de 4,50 m x 2,60 m cada baia, provido de bebedouro tipo chupeta e comedouro fixo semi-automático, de concreto com cinco divisões. Foram utilizados 200 suínos mestiços (Landrace x Large White) machos castrados, em crescimento, distribuídos em delineamento experimental inteiramente casualizado, com cinco tratamentos (níveis de $\mathrm{mEq} / \mathrm{kg}$ de ração suplementadas ou não com bicarbonato de sódio e/ou cloreto de potássio) e quatro repetições, onde a unidade experimental foi composta por dez animais na baia com peso médio inicial de 25,3 $\pm 1,3 \mathrm{~kg}$ e os mesmos permaneceram no experimento recebendo ração e água à vontade até atingirem o peso médio final de $68,8 \pm 3,4 \mathrm{~kg}$.

Os tratamentos foram compostos por cinco rações, sendo T1 (testemunha): ração sem suplementação de eletrólitos formulada com $191 \mathrm{mEq} / \mathrm{kg}$; T2 (supl. $\mathrm{NaHCO}_{3}$ ): ração com suplementação de bicarbonato de sódio $\left(\mathrm{NaHCO}_{3}\right.$ ) com $250 \mathrm{mEq} / \mathrm{kg}$; T3 (supl. $\mathrm{NaHCO}_{3}+\mathrm{KCl}$ ): ração com suplementação de $\mathrm{NaHCO}_{3}$ e cloreto de potássio $(\mathrm{KCl})$ formulada com $250 \mathrm{mEq} / \mathrm{kg}$; T4 (supl. $\mathrm{NaHCO}_{3}$ ): ração com suplementação de $\mathrm{NaHCO}_{3}$ formulada com $300 \mathrm{mEq} / \mathrm{kg}$; T5 (supl. $\mathrm{NaHCO}_{3}+\mathrm{KCl}$ ): ração com suplementação de $\mathrm{NaHCO}_{3}$ e $\mathrm{KCl}$ formulada com $300 \mathrm{mEq} / \mathrm{kg}$. As rações experimentais (Tabela 1) foram formuladas seguindo as recomendações de Rostagno et al. (2005), preparadas à base de milho e farelo de soja, para atender às exigências nutricionais de suínos machos castrados de alto potencial genético com desempenho médio na fase de crescimento.

Para a correção do balanço eletrolítico, as rações $\left(\mathrm{NaHCO}_{3}\right)$ continham bicarbonato de sódio $\left(\mathrm{NaHCO}_{3}\right)$ e as rações $\left(\mathrm{NaHCO}_{3}\right.$ e $\left.\mathrm{KCl}\right)$ continham bicarbonato de sódio e cloreto de potássio $(\mathrm{KCl})$, que foram adicionados em substituição ao milho da ração, sendo os demais ingredientes mantidos em sua concentração. Os valores de balanço eletrolítico (BE) das rações experimentais foram calculados, considerando o peso molecular de cada elemento químico, de acordo com a recomendação de Patience (1990). As condições ambientais do galpão foram monitoradas (às 7, 12 e 17 horas), utilizando termohigrômetro digital, termômetro de máxima e mínima e termômetro de globo negro, mantidos em uma baia vazia no centro do galpão à meia altura do corpo dos animais. As leituras dos equipamentos foram utilizadas para o cálculo do índice de temperatura de globo e umidade (ITGU), segundo metodologia de Buffington et al. (1981). Para o cálculo do ITGU, foi utilizada seguinte equação:

$$
\text { ITGU }=\text { Tgn }+0,36 \text { Tpo }-330,08
$$

Onde: ITGU = índice de temperatura de globo e umidade; Tgn $=$ temperatura de globo negro $\left({ }^{\circ} \mathrm{K}\right) ;$ Tpo = temperatura do ponto de orvalho $\left({ }^{\circ} \mathrm{K}\right)$.

Foram realizadas as pesagens diárias das sobras e do resíduo de ração. As pesagens dos animais foram realizadas no início e no final do experimento para a avaliação do ganho de peso. Para cálculo do consumo de 
nitrogênio foi considerado consumo de proteína bruta dividido pelo coeficiente 6,25 . A eficiência de lisina e de nitrogênio, ambos para ganho, foi avaliada pelo consumo médio de lisina necessário para os animais converterem em ganho de peso. Para a obtenção dos parâmetros fisiológicos, semanalmente, pela manhã (9 horas) foi obtida a temperatura retal de cada animal por meio de um termômetro clínico que era introduzido no reto de cada animal durante um minuto; ao mesmo tempo que foram feitas as mensurações de frequência respiratória obtida pela contagem dos movimentos dos flancos de cada animal durante 15 segundos. Esse resultado foi multiplicado por quatro para a obtenção da frequência respiratória em minutos. Ao final do período experimental foi realizada a coleta de sangue de cada animal, servindo-se de punção venosa do sinus orbital, utilizando-se agulha esterilizada e seca para a determinação das concentrações séricas de cloreto, sódio e potássio. As coletas foram realizadas duas horas após o fornecimento da ração pela manhã (09 horas). Os animais recebiam ração por 30 minutos, após esse período a mesma era vedada nos comedouros, esse procedimento foi realizado seguindo a metodologia de Dersjant-Li et al. (2002). As amostras de sangue foram coletadas em seringa plástica (COMB I- SAMPLER ${ }^{\circledR}$, Vented Syringe Kits- AVL) e devidamente identificadas e centrifugadas a $3.200 \mathrm{rpm}$ por cinco minutos para a obtenção do soro sanguíneo, posteriormente estocadas $\mathrm{a}-20^{\circ} \mathrm{C}$.

Tabela 1 - Composição das rações experimentais.

\begin{tabular}{|c|c|c|c|c|c|}
\hline \multirow[t]{2}{*}{ Ingredientes } & \multicolumn{5}{|c|}{ Dietas experimentais } \\
\hline & Testemunha & $\mathrm{NaHCO}_{3}$ & $\mathrm{NaHCO}_{3}+\mathrm{KCl}$ & $\mathrm{NaHCO}_{3}$ & $\mathrm{NaHCO}_{3}+\mathrm{KCl}$ \\
\hline Milho & 39,110 & 38,460 & 37,955 & 38,030 & 36,785 \\
\hline Sorgo & 30,000 & 30,000 & 30,000 & 30,000 & 30,000 \\
\hline Farelo de soja & 23,800 & 23,800 & 23,800 & 23,800 & 23,800 \\
\hline Óleo de soja & 2,600 & 2,600 & 2,600 & 2,600 & 2,600 \\
\hline Suplemento mineral:vitamínico ${ }^{(2)}$ & 4,000 & 4,000 & 4,000 & 4,000 & 4,000 \\
\hline Sal comum & 0,340 & 0,320 & 0,325 & 0,330 & 0,335 \\
\hline L- lisina $\mathrm{HCl}$ & 0,150 & 0,150 & 0,150 & 0,150 & 0,150 \\
\hline Bicarbonato de sódio & - & 0,670 & 0,670 & 1,090 & 1,330 \\
\hline Cloreto de potássio & - & - & 0,500 & - & 1,000 \\
\hline Total & 100,000 & 100,000 & 100,000 & 100,000 & 100,000 \\
\hline \multicolumn{6}{|c|}{ Composição Nutricional } \\
\hline Proteína Bruta $(\%)^{(1)}$ & 18,95 & 18,80 & 18,60 & 18,70 & 18,30 \\
\hline $\mathrm{EB}(\mathrm{kcal} / \mathrm{kg})^{(1)}$ & 3.470 & 3.468 & 3.466 & 3.467 & 3.464 \\
\hline $\mathrm{BE}(\mathrm{mEq} / \mathrm{kg})^{(3)}$ & 191 & 250 & 250 & 300 & 300 \\
\hline Lisina total $(\%)^{(1)}$ & 0,99 & 0,98 & 0,99 & 0,99 & 0,99 \\
\hline Cloreto $(\%)^{(4)}$ & 0,220 & 0,240 & 0,230 & 0,250 & 0,240 \\
\hline Sódio $(\%)^{(4)}$ & 0,270 & 0,390 & 0,380 & 0,500 & 0,490 \\
\hline Potássio $(\%)^{(4)}$ & 0,530 & 0,580 & 0,590 & 0,600 & 0,610 \\
\hline Cálcio $(\%)^{(4)}$ & 0,840 & 0,839 & 0,838 & 0,839 & 0,840 \\
\hline Fósforo total (\%) & 0,560 & 0,559 & 0,558 & 0,559 & 0,557 \\
\hline
\end{tabular}

${ }^{(1)}$ Composição calculada segundo Rostagno et al. (2005).

${ }^{(2)}$ Conteúdo em kg: Colina:4 g, sódio $54 \mathrm{~g}$, niacina $554 \mathrm{mg}$, zinco $2750 \mathrm{mg}$, vitamina E $280 \mathrm{mg}$, flúor (Max) $595 \mathrm{mg}$, biotina 1,5 mg, solubilidade do fósforo (P) em ácido cítrico a $2 \%(\mathrm{~min}) 90 \%$, vitamina K3 $56 \mathrm{mg}$, promotor de crescimento $2000 \mathrm{mg}$, cobre $3412 \mathrm{mg}$, vitamina B12 $700 \mathrm{mcg}$, fósforo $62 \mathrm{~g}$, vitamina D3 56000 ui/kg, ácido pantotênico $289 \mathrm{mg}$, vitamina A $140000 \mathrm{ui} / \mathrm{kg}$, riboflavina $112 \mathrm{mg}$, cobalto 4,6 mg, selênio $9 \mathrm{mg}$, tiamina $28 \mathrm{mg}$, antioxidante $9 \mathrm{mg}$.

${ }^{(3)} \mathrm{BE}$ - Balanço eletrolítico da ração calculado conforme Patience (1990), $\mathrm{BE}=(\mathrm{Na} / 23+\mathrm{K} / 39-\mathrm{Cl} / 35,5) \mathrm{x} 1000$.

${ }^{(4)}$ Análises realizadas no Laboratório de Solos - Universidade Estadual do Maranhão - UEMA. 
O modelo estatístico utilizado foi $Y i j=\mu+t i+$ eij, em que $\mathrm{Yij}=$ efeito do tratamento $\mathrm{i}$ na repetição $\mathrm{j}, \mu=$ média geral das variáveis, $t i=$ efeito do tratamento $i$, eij $=$ erro aleatório associado a cada observação ij. As análises estatísticas para o desempenho e parâmetros fisiológicos do sangue foram realizadas, utilizando-se os procedimentos do SAS versão 7.0 (SAS Institute, 2005), efetuando-se a soma de quadrados dos tratamentos decompostas em contrastes ortogonais para análise dos efeitos de balanço eletrolítico considerando o nível de 5\% de probabilidade.

\section{RESULTADOS E DISCUSSÃO}

Durante todo o período experimental a temperatura média manteve-se em $29,65 \pm 3,80^{\circ} \mathrm{C}$, com umidade relativa do ar de $69,6 \pm 10,4 \%$ e temperatura do globo negro de $31,95 \pm 1,98^{\circ} \mathrm{C}$. O índice de temperatura de globo e umidade (ITGU) foi calculado em $80,51 \pm 2,44$. A temperatura média observada de $31,95^{\circ} \mathrm{C}$ pode ser caracterizada como estresse por calor para suínos em fase de crescimento (25 aos $70 \mathrm{~kg}$ ). De acordo com DAMASCENO et al. (2010), estes índices de conforto térmico são utilizados para quantificar e qualificar o desconforto térmico animal, que por sua vez, podem estar relacionados às respostas fisiológicas e desempenho produtivo dos animais, sendo um método de avaliação indireto e relativamente prático. Orlando et al. (2007) descreve como faixa ideal de temperatura para conforto térmico para esta categoria animal sendo de 16 a $24^{\circ} \mathrm{C}$. A umidade relativa média do ar verificada está de acordo com os parâmetros recomendados para a criação de suínos (70 a 80\%), conforme apresentado em Tolon (2010). Estudos conduzidos com suínos mantidos em condições de calor apresentaram valores semelhantes de ITGU conforme descrito por Orlando et al. (2007) e Ferreira et al. (2007), sendo ambos em torno de 83 caracterizando estresse por calor para suínos.

Os resultados de consumo, ganho de peso, conversão alimentar, peso final, consumo de nitrogênio, consumo de lisina, eficiência de utilização de lisina para ganho e eficiência de utilização do nitrogênio para ganho são apresentados na Tabela 2.

A suplementação de eletrólitos piorou $(\mathrm{P}<0,05) \mathrm{o}$ consumo de ração dos animais. Observou-se que os suínos que receberam a suplementação de eletrólitos nas rações apresentaram redução média de $1,17 \%$ no consumo quando

Tabela 2 - Desempenho de suínos em crescimento, mantidos em condições naturais de calor recebendo rações com diferentes balanços eletrolíticos.

\begin{tabular}{|c|c|c|c|c|c|c|c|c|}
\hline \multirow[b]{2}{*}{ Tratamentos } & \multicolumn{8}{|c|}{ Variáveis Analisadas } \\
\hline & $\begin{array}{c}\mathrm{CR} \\
\text { (g/dia) }\end{array}$ & $\begin{array}{c}\mathrm{GP} \\
(\mathrm{g} / \mathrm{dia})\end{array}$ & CA & $\begin{array}{l}\mathrm{PF} \\
(\mathrm{kg})\end{array}$ & $\begin{array}{c}\mathrm{CN} \\
\text { (g/dia) }\end{array}$ & $\begin{array}{c}\mathrm{CL} \\
(\mathrm{g} / \mathrm{dia})\end{array}$ & $\begin{array}{l}\text { EUNG } \\
\text { (g/dia) }\end{array}$ & $\begin{array}{l}\text { EULis } \\
(\mathrm{gGP} / \mathrm{gN})\end{array}$ \\
\hline Testemunha & 2.558 & 1.176 & 2,18 & 73,55 & 77,54 & 25,32 & 14,94 & 45,76 \\
\hline $\mathrm{NaHCO}_{3} 250 \mathrm{mEq} / \mathrm{kg}$ & 2.517 & 1.159 & 2,17 & 73,00 & 75,70 & 24,66 & 15,54 & 47,69 \\
\hline $\mathrm{NaHCO}_{3}+\mathrm{KCl} 250 \mathrm{mEq} / \mathrm{kg}$ & 2.546 & 1.164 & 2,19 & 72,70 & 75,76 & 25,31 & 15,32 & 46,06 \\
\hline $\mathrm{NaHCO}_{3} 300 \mathrm{mEq} / \mathrm{kg}$ & 2.540 & 1.228 & 2,06 & 75,63 & 75,99 & 25,14 & 16,29 & 48,76 \\
\hline $\mathrm{NaHCO}_{3}+\mathrm{KCl} 300 \mathrm{mEq} / \mathrm{kg}$ & 2.507 & 1.135 & 2,20 & 72,53 & 70,46 & 23,82 & 16,25 & 47,29 \\
\hline $\mathrm{CV}(\%)$ & 3,85 & 3,76 & 4,76 & 4,79 & 3,64 & 4,16 & 3,35 & 4,96 \\
\hline Contrastes & \multicolumn{8}{|c|}{ Significância } \\
\hline Testemunha vs demais dietas & * & 0,15 & 0,52 & 0,13 & $*$ & 0,27 & 0,12 & 0,23 \\
\hline $\begin{array}{l}\mathrm{NaHCO}_{3} 250 \mathrm{mEq}+ \\
\mathrm{NaHCO}_{3}+\mathrm{KCl} 250 \mathrm{mEq} \\
\text { vs } \mathrm{NaHCO}_{3} 300 \mathrm{mEq}\end{array}$ & 0,91 & 0,12 & 0,54 & 0,19 & $*$ & 0,30 & 0,10 & 0,20 \\
\hline $\begin{array}{l}+\mathrm{NaHCO}_{3}+\mathrm{KCl} 300 \mathrm{mEq} \\
\mathrm{NaHCO}_{3} 250 \mathrm{mEq} \text { vs } \\
\mathrm{NaHCO}_{3}+\mathrm{KCl} 250 \mathrm{mq}\end{array}$ & 0,93 & 0,17 & 0,53 & 0,21 & 0,25 & 0,35 & 0,14 & 0,21 \\
\hline $\begin{array}{l}\mathrm{NaHCO}_{3} 300 \mathrm{mEq}+ \\
\mathrm{NaHCO}_{3}+\mathrm{KCl} 300 \mathrm{mEq}\end{array}$ & 0,95 & 0,20 & 0,59 & 0,17 & 0,21 & 0,33 & 0,15 & 0,19 \\
\hline
\end{tabular}

*significativo $5 \%$ pelo teste $\mathrm{T}$.

CR (consumo de ração); GP (ganho de peso); CA(conversão alimentar); PF (peso final); CN (consumo de nitrogênio); CL (consumo de lisina); EUNG (eficiência de utilização de nitrogênio); EULis (eficiência de utilização de lisina). 
comparado com animais que não receberam ração com o balanço eletrolítico corrigido. A ingestão de sódio pode provocar sede, aumento no consumo de água e expansão do volume extracelular e, consequentemente, pode reduzir o consumo de ração. Isso pode ter ocorrido em função do nível de sódio estar acima das exigências $(0,18 \%)$, de acordo com Rostagno et al. (2005), porém abaixo do nível para toxidez $(3,2 \%)$ para espécie suína. É oportuno salientar que não foram observadas diferenças $(\mathrm{P}>0,05)$ no ganho de peso, conversão alimentar e peso final dos animais, demonstrando que a suplementação não contribuiu para melhorar o desempenho dos suínos. Esse resultado foi semelhante ao obtido por Budde \& Crenschaw (2003) que relataram que mudanças no balanço eletrolítico (BE) na ração de -35 a $212 \mathrm{mEq} / \mathrm{kg}$ não afetaram o ganho de peso de suínos em crescimento. Lizardo (2006), em revisão sobre uso de bicarbonato de sódio na alimentação de suínos, concluiu que a mudança na ingestão voluntária de ração poderia ser uma resposta às variações do balanço eletrolítico, o que caracterizaria a existência de um mecanismo que permitiria limitar os efeitos de uma ração muito ácida ou muito básica. Esse resultado foi de encontro aos publicados por Haydon \& West (1990), quando foi observada melhora nos resultados de conversão alimentar ao serem utilizadas rações com maiores concentrações de eletrólitos. Segundo os autores, esse fato pode estar relacionado ao melhor aproveitamento dos nutrientes da ração no intestino delgado.
Os resultados observados para a consumo de nitrogênio foram influenciados $(\mathrm{P}<0,05)$ pela correção de balanço eletrolítico e pelos teores de sais utilizados. $\mathrm{O}$ maior consumo de nitrogênio foi observado pelos animais que receberam ração sem a suplementação de eletrólitos, fato esse que decorreu em função do maior consumo de ração observado. A variação observada no consumo de nitrogênio dentre as demais dietas experimentais acompanhou a flutuação numérica observada no teor de proteína bruta das rações.

Apesar da influência sobre o consumo de nitrogênio, verificou-se que a correção do balanço eletrolítico nesse experimento não influenciou $(\mathrm{P}>0,05)$ os resultados de consumo de lisina e eficiência de utilização de lisina para ganho e para nitrogênio.

Os resultados dos consumos diários de sódio, potássio e cloro apresentados por suínos em fase de crescimento, alimentados com rações contendo diferentes balanços eletrolíticos estão demonstrados na Tabela 3 .

A suplementação de eletrólitos não afetou $(\mathrm{P}>0,05)$ os consumos de sódio e potássio, porém a mesma afetou $(\mathrm{P}<0,05)$ o consumo de cloreto. Notou-se que os animais que receberam rações com $300 \mathrm{mEq} / \mathrm{kg}$ apresentaram consumo de cloreto $1,5 \%$ a mais que aqueles que receberam rações com $250 \mathrm{mEq} / \mathrm{kg}$. Esse fato pode ter influenciado positivamente a eficiência de utilização de nitrogênio e a eficiência de utilização de lisina para os animais que receberam rações com $300 \mathrm{mEq} / \mathrm{kg}$

Tabela 3 - Consumos de sódio, potássio e cloreto por suínos em fase de crescimento, alimentados com rações contendo diferentes balanços eletrolíticos.

\begin{tabular}{|c|c|c|c|}
\hline \multirow{2}{*}{ Tratamentos } & \multicolumn{3}{|c|}{ Consumo diário } \\
\hline & Sódio & Potássio & Cloreto \\
\hline Testemunha & 9,91 & 13,56 & 5,63 \\
\hline $\mathrm{NaHCO}_{3} 250 \mathrm{mEq} / \mathrm{kg}$ & 9,81 & 14,60 & 5,91 \\
\hline $\mathrm{NaHCO}_{3}+\mathrm{KCl} 250 \mathrm{mEq} / \mathrm{kg}$ & 9,77 & 15,17 & 6,04 \\
\hline $\mathrm{NaHCO}_{3} 300 \mathrm{mEq} / \mathrm{kg}$ & 11,79 & 14,68 & 5,77 \\
\hline $\mathrm{NaHCO}_{3}+\mathrm{KCl} 300 \mathrm{mEq} / \mathrm{kg}$ & 12,69 & 15,24 & 6,35 \\
\hline $\mathrm{CV}(\%)$ & 4,02 & 4,38 & 5,11 \\
\hline \multicolumn{4}{|l|}{ Contrastes } \\
\hline Testemunha vs demais dietas & 0,71 & 0,51 & 0,24 \\
\hline $\mathrm{NaHCO}_{3} 250 \mathrm{mEq}+\mathrm{NaHCO}_{3}+\mathrm{KCl} 250 \mathrm{mEq} \mathrm{VS}$ & 0,73 & 0,52 & $*$ \\
\hline $\begin{array}{l}\mathrm{NaHCO}_{3} 300 \mathrm{mEq}+\mathrm{NaHCO}_{3}+\mathrm{KCl} 300 \mathrm{mEq} \\
\mathrm{NaHCO}_{3} 250 \mathrm{mEq} \text { vsNaHCO} \\
3\end{array}$ & 0,75 & 0,54 & 0,25 \\
\hline $\mathrm{NaHCO}_{3} 300 \mathrm{mEq}+\mathrm{NaHCO}_{3}+\mathrm{KCl} 300 \mathrm{mEq}$ & 0,78 & 0,56 & 0,29 \\
\hline
\end{tabular}

*significativo $5 \%$ pelo teste $\mathrm{T}$. 
em relação aos que receberam $250 \mathrm{mEq} / \mathrm{kg}$. Os resultados observados para o consumo de potássio na ração não foram diferentes $(\mathrm{P}>0,05)$ entre as dietas experimentais avaliadas. É importante ressaltar que o equilíbrio de potássio somente é atingido quando ocorre igualdade entre a quantidade ingerida pelo consumo de ração com a quantidade excretada, sendo que esta regulagem é função principalmente dos rins. O mecanismo regulador baseia-se na permuta com o sódio nos túbulos renais e a retenção de sódio é acompanhada pela eliminação de potássio (Évora, 1999).

Os resultados observados para consumo de cloreto na ração foram diferentes $(\mathrm{P}<0,05)$ entre as rações que apresentaram a correção do balanço eletrolítico. De acordo com Salvador et al. (1999), o aumento do cloreto plasmático favorece a retenção de $\mathrm{H}^{+}$e diminuição da reabsorção de íon bicarbonato $\left(\mathrm{HCO}_{3}^{-}\right)$pelos rins, sendo esta uma resposta à alcalose metabólica. Os tratamentos com $\mathrm{NaHCO}_{3} 300 \mathrm{mEq}$ e $\mathrm{NaHCO}_{3}+\mathrm{KCl} 300 \mathrm{mEq}$ utilizando o balanço eletrolítico de $300 \mathrm{mEq} / \mathrm{kg}$ apresentaram maior relação $\mathrm{Na}: \mathrm{Cl}$ aproximadamente (2,04:1 e 2,00:1), respectivamente. O bicarbonato de sódio é uma fonte de eletrólitos que apresenta a vantagem de contribuir com sódio sem incorporar o cloro. No entanto, as necessidades de cloro são inferiores às de sódio e o uso de cloreto de potássio deve ser limitado até a satisfação das necessidades de cloro, assim que este se complementa com as necessidades de sódio.

Os resultados da concentração de sódio, potássio e cloreto no soro de suínos estão demonstrados na Tabela 4.
Podem ser verificados, na Tabela 4, os resultados observados para concentração sérica de sódio não foram diferentes $(\mathrm{P}>0,05)$ entre os tratamentos analisados. A maior concentração sérica de sódio, não significativa, nas rações com $\mathrm{NaHCO}_{3} 300 \mathrm{mEq} / \mathrm{kg}$ (bicarbonato de sódio) e $\mathrm{NaHCO}_{3}+\mathrm{KCl} 300 \mathrm{mEq} / \mathrm{kg}$ (bicarbonato de sódio e cloreto de potássio), provavelmente foram responsáveis pela ação do hormônio aldosterona que tem como função a reabsorção de sódio no organismo. De acordo com Jardim et al. (1987), os valores mensurados para suínos machos castrados pesando entre 50 e $90 \mathrm{~kg}$ foram de 152,1 $\pm 18,3 \mathrm{mEq} / \mathrm{L}$. Os resultados observados para concentração sérica de potássio foram diferentes $(\mathrm{P}<0,05)$ entre os as rações com $\mathrm{NaHCO}_{3} 300 \mathrm{mEq} / \mathrm{kg}$ e $\mathrm{NaHCO}_{3}+\mathrm{KCl} 300 \mathrm{mEq} / \mathrm{kg}$ analisados. O alto consumo de potássio ocorrido nesta ração pode ter contribuído para um aumento da excreção urinária desse elemento, em decorrência de sua maior secreção no ducto coletor. Como consequência, ocorreu diminuição no nível sérico de potássio para esta ração, onde se aproximou do limite mínimo (4,4 mEq/L) citado por Osweiller \& Hurd (1974) para a espécie suína. Entretanto, Jardim et al. (1987) observaram em sua pesquisa com suínos machos castrados com peso vivo entre 50-90 kg um valor médio de $5,9 \pm 1,3 \mathrm{mEq} / \mathrm{L}$ de potássio. Portanto, mais potássio pode ter sido transportado para o espaço tubular nos glomérulos, ocasionando maior excreção urinária deste elemento, em decorrência do aumento na concentração de aldosterona (Dibartola et al., 2007). Provavelmente, a ingestão de potássio na ração com bicarbonato de sódio e cloreto de potássio $300 \mathrm{mEq} / \mathrm{kg}$ atingiu o limiar de excreção, pelo fato de os animais tentarem manter

Tabela 4 - Concentrações séricas de íons em mEq/L de suínos em crescimento alimentados com rações contendo diferentes balanços eletrolíticos.

\begin{tabular}{|c|c|c|c|}
\hline \multirow{2}{*}{ Tratamentos } & \multicolumn{3}{|c|}{ Íons } \\
\hline & Sódio & Potássio & Cloreto \\
\hline Testemunha & 139,25 & 4,93 & 101,00 \\
\hline$\left(\mathrm{NaHCO}_{3} 250 \mathrm{mEq} / \mathrm{kg}\right)$ & 137,50 & 5,08 & 100,50 \\
\hline$\left(\mathrm{NaHCO}_{3}+\mathrm{KCl} 250 \mathrm{mEq} / \mathrm{kg}\right)$ & 138,50 & 5,35 & 102,00 \\
\hline$\left(\mathrm{NaHCO}_{3} 300 \mathrm{mEq} / \mathrm{kg}\right)$ & 140,25 & 4,95 & 100,25 \\
\hline$\left(\mathrm{NaHCO}_{3}+\mathrm{KCl} 300 \mathrm{mEq} / \mathrm{kg}\right)$ & 140,25 & 4,58 & 100,50 \\
\hline $\mathrm{CV}(\%)$ & 2,69 & 3,95 & 3,58 \\
\hline Contrastes & & & \\
\hline Testemunha vs demais dietas & 0,16 & 0,24 & 0,32 \\
\hline $\begin{array}{l}\mathrm{NaHCO}_{3} 250 \mathrm{mEq}+\mathrm{NaHCO}_{3}+\mathrm{KCl} 250 \mathrm{mEq} \text { vs } \mathrm{NaHCO}_{3} 300 \\
\mathrm{mEq}+\mathrm{NaHCO}_{3}+\mathrm{KCl} 300 \mathrm{mEq}\end{array}$ & 0,15 & 0,26 & 0,30 \\
\hline $\mathrm{NaHCO}_{3} 250 \mathrm{mEq}$ vs $\mathrm{NaHCO}_{3}+\mathrm{KCl} 250 \mathrm{mEq}$ & 0,19 & 0,29 & 0,34 \\
\hline $\mathrm{NaHCO}_{3} 300 \mathrm{mEq}$ vs $\mathrm{NaHCO}_{3}+\mathrm{KCl} 300 \mathrm{mEq}$ & 0,18 & $*$ & 0,35 \\
\hline
\end{tabular}

*significativo $5 \%$ pelo teste $\mathrm{T}$. 
constante o equilíbrio eletrolítico. Savaris (2009), observou em seu estudo do balanço eletrolítico em suínos em crescimento, que a maior ingestão de potássio foi observada nos animais que consumiram a ração com balanço eletrolítico de $260 \mathrm{mEq} / \mathrm{kg}$, onde foi atingido o nível crítico dessa excreção, portanto esse fato foi o motivo dos animais tentarem manter constante seu balanço eletrolítico sanguíneo.

Os resultados observados para concentração sérica de cloreto não foram diferentes $(\mathrm{P}>0,05)$ entre as rações analisadas. Os valores do soro sanguíneo estão dentro das referências para cloreto (94-106 mEq/L) de acordo com Universidade Estadual Paulista - Unesp (1996). Segundo Dersjant-Li et al. (2002), o aumento do balanço eletrolítico nas rações ocasionou uma redução nos níveis de cloreto no plasma e no soro sanguíneo.

Os resultados referentes às respostas fisiológicas de frequência respiratória (FR) e temperatura retal (TR) apresentados pelos animais estão na Tabela 5 .

Os resultados observados para frequência respiratória (FR) e para temperatura retal (TR) não foram diferentes $(\mathrm{P}>0,05)$ entre os tratamentos analisados. No plasma, uma parte do $\mathrm{CO}_{2}$ interage com substâncias tamponantes no interior dos eritrócitos, outra fração considerável reage com a hemoglobina para formar compostos carbamino- $\mathrm{CO}_{2}$ e o restante do $\mathrm{CO}_{2}$ é hidratado para formar o ácido carbônico $\left(\mathrm{H}_{2} \mathrm{CO}_{3}\right)$ que é o mais importante ácido formado no catabolismo dos nutrientes (Macari et al., 1999).

Conforme Borges et al. (2003), animais submetidos a continuado estresse por calor, têm aumento da frequência respiratória, resultando em perdas excessivas de dióxido de carbono, que conduz a diminuição da pressão de $\mathrm{CO}_{2}$, levando a queda na concentração de ácido carbônico e hidrogênio. Isso caracteriza a ocorrência de alcalose respiratória, em razão da excessiva eliminação de dióxido de carbono.

Qualquer elevação maior na temperatura ambiente, acima daquela considerada como conforto térmico, pode causar aumento da temperatura corporal desses animais. Logo, os valores encontrados pelos tratamentos promoveram um adequado controle homeotérmico nesses animais. Os resultados encontrados para frequência respiratória e temperatura retal foram inferiores aos resultados encontrados por Tavares et al. (2000) e Orlando et al. (2007), ambos de $39,4^{\circ} \mathrm{C}$.

Tabela 5 - Resultado de frequência respiratória (FR) em movimento por minuto (mov/min) e temperatura retal (TR) em $\left({ }^{\circ} \mathrm{C}\right)$ de suínos em crescimento dos 25 aos $68,8 \mathrm{~kg}$ alimentados com rações contendo diferentes balanços eletrolíticos.

\begin{tabular}{|c|c|c|}
\hline Tratamentos & FR (mov/min) & $\mathrm{TR}\left({ }^{\circ} \mathrm{C}\right)$ \\
\hline Testemunha & $71,24 \pm 1,26$ & $39,61 \pm 0,02$ \\
\hline$\left(\mathrm{NaHCO}_{3} 250 \mathrm{mEq} / \mathrm{kg}\right)$ & $67,92 \pm 1,05$ & $39,59 \pm 0,01$ \\
\hline$\left(\mathrm{NaHCO}_{3}+\mathrm{KCl} 250 \mathrm{mEq} / \mathrm{kg}\right)$ & $65,91 \pm 0,95$ & $39,59 \pm 0,03$ \\
\hline$\left(\mathrm{NaHCO}_{3} 300 \mathrm{mEq} / \mathrm{kg}\right)$ & $61,79 \pm 0,83$ & $39,51 \pm 0,07$ \\
\hline$\left(\mathrm{NaHCO}_{3}+\mathrm{KCl} 300 \mathrm{mEq} / \mathrm{kg}\right)$ & $67,91 \pm 1,08$ & $39,62 \pm 0,03$ \\
\hline $\mathrm{CV}(\%)$ & 5,12 & 2,26 \\
\hline Contrastes & \multicolumn{2}{|c|}{ Significância } \\
\hline Testemunha vs demais dietas & 0,34 & 0,26 \\
\hline $\begin{array}{l}\mathrm{NaHCO}_{3} 250 \mathrm{mEq}+\mathrm{NaHCO}_{3}+\mathrm{KCl} 250 \mathrm{mEq} \text { vs } \\
\mathrm{NaHCO}_{3} 300 \mathrm{mEq}+\mathrm{NaHCO}_{3}+\mathrm{KCl} 300 \mathrm{mEq}\end{array}$ & 0,32 & 0,25 \\
\hline $\mathrm{NaHCO}_{3} 250 \mathrm{mEq}$ vs $\mathrm{NaHCO}_{3}+\mathrm{KCl} 250 \mathrm{mEq}$ & 0,33 & 0,22 \\
\hline $\mathrm{NaHCO}_{3} 300 \mathrm{mEq}$ vs $\mathrm{NaHCO}_{3}+\mathrm{KCl} 300 \mathrm{mEq}$ & 0,30 & 0,23 \\
\hline
\end{tabular}




\section{CONCLUSÕES}

A correção do balanço eletrolítico em rações contendo 250 ou $300 \mathrm{mEq} / \mathrm{kg}$, suplementadas com bicarbonato de sódio e/ou cloreto de potássio, não influenciou o desempenho de suínos em crescimento (25-70 kg). Os resultados encontrados pelos tratamentos indicam que o mecanismo de controle homeotérmico foi eficiente nesses animais.

\section{AGRADECIMENTOS}

Aos funcionários, em especial, ao Gerente Geral o Sr. José de Souza da Granja Agrolusa S/A, localizada em São Luis - Maranhão.

\section{REFERÊNCIAS BIBLIOGRÁFICAS}

BORGES, S.A.; SILVA, A.V.F. da; ARIKI, J.; HOODE, D.M.; CUMMINGS, K.R. Dietary electrolyte balance for broiler chickens exposed to thermoneutral or heat-stress environments. Poultry Science, London, v.82, p.428-435, 2003.

BUDDE, R.A.; CRENSCHAW, F.D. Chronic metabolic acid load induced by changes in dietary electrolyte balance increased chloride retention but did not compromise bone in growing swine. Journal of Animal Science, Champaign, v.81, p.197-208, 2003.

BUFFINGTON, D.E.; COLAZZO-AROCHO, A.; CANTON, G.H. Black golbe-humidity índex (BGHI) as confort equation for dairy cows. Transaction of the ASAE, Amsterdam, v.24, p.711-714, 1981.

CARVALHO, L.E.; OLIVEIRA, S.M.; TURCO, S.H.N. Utilização da nebulização e ventilação forçada sobre o desempenho e a temperatura da pele de suínos na fase de terminação. Revista Brasileira de Zootecnia, Viçosa, v.33, n.6, p.486-1491, 2004.

DAMASCENO, F.A.; JUNIOR, T.Y.; LIMA, R.R. de; GOMES, R.C.C.; MORAES, S.R.P. de. Avaliação do bemestar de frangos de corte em dois galpões comerciais climatizados. Ciência e Agrotecnologia, Lavras, v.34, n.4, p.1031-1038, jul./ago., 2010.

DERSJANT-LI, Y.; VERSTEGEN, M.N.A.; JANSMAN, A. Changes in oxygen content and acid-base balance in arterial and portal blood in response to the dietary electrolyte balance in pigs during a 9 -h period aften a meal. Journal of Animal Science, Champaign, v.80, p.1233-1239, 2002.
DIBARTOLA, S.P. Anormalidades de fluidos, eletrólitos e equilíbrio ácido-básico na clínica de pequenos animais. 3.ed. São Paulo: Rocca, 2007. $664 \mathrm{p}$.

ÉVORA, P.R.B.; REIS, C.L.; FEREZ, M.A.; CONTE, D.A. Distúrbios do equilíbrio hidroeletrolítico e do equilíbrio ácido-básico. Medicina, Ribeirão Preto, v.32, p.451-469, 1999.

FERREIRA, R.A.; OLIVEIRA, R.F.M.; DONZELE, J.L.; SARAIVA, E.P. Redução da proteína bruta e suplementação de aminoácidos para suínos machos castrados dos 30 aos $60 \mathrm{~kg}$ mantidos em ambiente de alta temperatura. Revista Sociedade Brasileira de Zootecnia, Viçosa, v.36, n.4, p.818-824, 2007.

HAYDON, K.D.; WEST, J.W.; McCARTER, M.N. Effect of dietary electrolyte balance on performance and blood parameters of ambient temperatures growing- finishing swine feed in high. Journal of Animal Science, Champaign, v.68, p.2400-2406, 1990.

JARDIM, E.C.; FISCHTNER, S.S.; ZAPATA, H.S.S. Teores séricos de cálcio, fósforo, sódio e potássio em suínos no Estado de Goiás. Anais da Escola de Agronomia e Veterinária, v.17, p.107-111, 1987.

LIZARDO, R. O bicarbonato de sódio na alimentação dos suínos. Revista SUIS Brasil, n.11, p.14-23, 2006.

MACARI, M.; FURLAN, R.L.; GONZALES, E. Fisiologia aviária aplicada a frangos de corte. Jaboticabal: FUNEP/ UNESP, 1999. 246p.

MOGIN, P. Electrolytes in nutrition. 3.ed. Orlando: International Minerals, 1980. 16p.

ORLANDO, U.A.D.; OLIVEIRA, R.F.M.; DONZELE, J.L.; SILVA, F.C.O. Níveis de proteína bruta e suplementação de aminoácidos em rações para leitoas dos 30 aos $60 \mathrm{~kg}$ mantidas em ambiente de alta temperatura. Revista Brasileira de Zootecnia, Viçosa, v.36, n.5, p.1573-1578, 2007. Suplemento.

OSWEILLER, G.D.; HURD, J.W. Determination of sodium contend in serum ans cerebrospinal fluid and adjunct to diagnosis of water deprivation in swine. Journal Biological Chemistry, v.15, p.1657-1670, 1974. 
PATIENCE, J.F. A review of the role of acid-base balance in amino acid nutrition. Journal of Animal Science, Champaign, v.68, p.398-408, 1990.

ROSTAGNO, H.S.; ALBINO, L.F.T.; DONZELE, J.L. Tabelas brasileiras para aves e suínos: composição de alimentos e exigências nutricionais. Viçosa, MG: UFV, 2005. 186p.

SALVADOR, D.; PORTSMOUTH, J. Suplementação de bicarbonato sódio na ração e na água de bebida de frangos de corte submetidos ao estresse calórico. ARS Veterinária, v.15, p.144-148, 1999.

SAS INSTITUTE. Statistical analysis system: realize 7.0. Cary, 2005. 620p.

SAVARIS, V.D.L. Estudos do balanço eletrolítico e da proteína bruta da ração para suínos em crescimento em condições de alta temperatura. Ciência e

Agrotecnologia, Lavras, v.41, n.4, p.818-824, 2009.
TAVARES, S.L.S.; DONZELE, J.L.; OLIVEIRA, R.F.M.; FERREIRA, A.S. Influência da temperatura sobre o desempenho e os parâmetros fisiológicos de suínos machos castrados dos 30 aos $60 \mathrm{~kg}$. Revista Brasileira de Zootecnia, Viçosa, v.29, n.1, p.199-205, 2000.

TOLON, Y.; BARACHO, M.S.; NÄÄS, I. de A.; ROJAS, M. Ambiência térmica, aérea e acústica para reprodutores suínos. Engenharia Agrícola, Jaboticabal, v.30, n.1, p.1-13, 2010

UNIVERSIDADE ESTADUAL PAULISTA. Tabela de valores normais de eletrólitos em diferentes espécies animais., Botucatu, 1996.

VIEITES, F.M.; MORAES, G.H.K.; ALBINO, L.F.T.; ROSTAGNO, H.S. Balanço eletrolítico e níveis de proteína bruta sobre o desempenho de pintos de corte de 1 a 21 dias de idade. Revista Brasileira de Zootecnia, Viçosa, v.33, n.6, p.2076-2085, 2004. Suplemento. 